\title{
Disciplina y violencia contra las mujeres en la prensa del siglo XIX. Divergencia comparativa entre México y España
}

\author{
Sara Esperanza Sanz Reyes ${ }^{1}$ (i) 0000-0001-8161-2612 \\ Jordi Luengo López ${ }^{2}$ (i) 0000-0001-5564-9892 \\ 'Universidad Nacional Autónoma de México, Escuela Nacional de Estudios Superiores, \\ Mérida, Yucatán, México. \\ ${ }^{2}$ Universidad Pablo Olavide, Sevilla, Andalucía, España. 41013
}

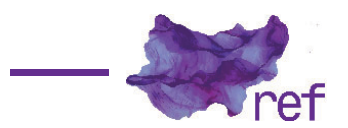

Resumen: En este artículo se analizan de forma comparativa las formas de representación de las mujeres y su conducta en los medios impresos tanto en México como España a finales del siglo XIX $y$ principios del XX. Se distingue entre la prensa dirigida a las mujeres, la que se escribe a partir de la narración de crímenes y la que producen ellas mismas sobre sus circunstancias. En primer lugar, se encuentra una férrea regulación de los espacios que deben ocupar a partir de la descripción de sus actividades domésticas y maternas. En segundo lugar, la sanción de su disidencia generando estereotipos que las criminalizaban o disuadían de lo terrible de la violencia en su contra y, finalmente, las letras femeninas que acudían a la opinión pública para el reconocimiento de sus nuevas tareas y la exigencia de recibir una educación.

Palabras clave: prensa del siglo XIX; mujeres; disciplina; violencia; comparación entre México y España.

\begin{abstract}
Discipline and Violence Against Women in the 19th Century Press. Comparative Divergence Between Mexico and Spain

Abstract: This article presents a comparative analysis of the ways women, and their behaviour were represented in the print media in Mexico and Spain at the end of the 19th and beginning of the 20th century. The study distinguishes between the press specifically addressed at women, the press based on accounts of crimes, and that written by women about their own circumstances. The analysis uncovers, first, an unyielding regulation of the spaces women were obliged to occupy, through descriptions of their domestic and maternal activities; second, punishment of women's dissidence by generating criminalising stereotypes or belying the atrocity of the violence against them; and third, writings by women calling for public recognition of their new tasks and demanding education.
\end{abstract}

Keywords: 19th century press; Women, Discipline; Violence; Comparison between Mexico and Spain.

\footnotetext{
Disciplina e violência contra as mulheres na imprensa do século XIX. Divergência comparativa entre o México e a Espanha

Resumo: Neste artigo, são analisadas comparativamente as formas de representação das mulheres e o seu comportamento na mídia impressa no México e na Espanha no final do século XIX e início do século XX. Faz-se uma distinção entre a imprensa dirigida às mulheres, aquela que é escrita com base na narração de crimes, e aquela que elas mesmas produzem sobre as suas circunstâncias. Em primeiro lugar, há uma regulamentação rigorosa dos espaços que devem ocupar a partir da descrição das suas atividades domésticas e maternas. Em segundo lugar, há uma sanção da sua dissidência, gerando, assim, estereótipos que criminalizavam ou dissuadiam a terrível violência contra elas e, finalmente, as letras femininas que apelavam à opinião pública para o reconhecimento das suas novas tarefas e para exigir educação.

Palavras-chave: imprensa do século XIX; mulheres; disciplina; violência; comparação entre México e Espanha.
} 


\section{Introducción}

En el ocaso del período finisecular, en la primera plana del diario El Telegrama (18861892) de circulación en la Península de Yucatán (México), aparece un artículo que hace alusión al movimiento por el sufragio femenino estadounidense, señalando que sería una catástrofe social dar la oportunidad a las mujeres de votar y participar en política "iElegibles!... gran Dios! Que desorden tan espantoso se vería". ' La nota se titulaba "Las mujeres al Congreso", y describía una condición inaceptable, de perjuicio para las familias, y el propio servicio público. Una reacción idéntica describe Mornat en España, a través de un estudio de 15 publicaciones en las cuales da cuenta de las reacciones antifeministas tanto en las letras como la iconografía respecto al movimiento sufragista inglés. El rechazo se evidenciaba a partir de declaraciones como la de Faustina Saéz de Melgar (1834-1895) en el diario Iberia (1854-1898) cuando, al expresar su deseo de abrir un Ateneo de Señoras, en 1869, dijo que su idea educativa estaba lejos de pedir derechos políticos y la emancipación de la mujer (Isabelle MORNAT, 2016, p. 2). Al mismo tiempo, se extendía el estereotipo de que las mujeres interesadas en la política eran varoniles o al contrario, hipersexualizadas.

En el último tercio del siglo XIX, el mundo se estaba transformando por el crecimiento de la industrialización, modernización y trabajo asalariado, tanto así por la difusión de las ideas del liberalismo. Las familias, la forma de relacionarse e incluso las nociones de niñez se modificaron de forma acelerada y encontraban resistencias. Por tal motivo, en este artículo nos proponemos describir los elementos comunes y divergentes entre la representación de las mujeres en la prensa española y mexicana, así como la función que asumieron los medios escritos en la corrección de sus conductas a través de metáforas sobre la violencia ejercida contra las mujeres como disciplina o deleite estético.

El balance historiográfico y las fuentes primarias son del último tercio del período decimonónico y principios del pasado siglo. La elección es porque en este periodo la definición de masculino y femenino se distinguió atendiendo a los roles desempeñados por las mujeres en el espacio doméstico, reforzados con el imperativo de cumplir con una maternidad social. Para los hombres, su rol productivo iba aparejado con la obligación de una moralidad. En contraposición, se ignoraron las tareas que ya desempeñaban las mujeres en los espacios públicos, además de las nuevas que fueron llamadas a cumplir de acuerdo con las necesidades económicas y laborales.

Los estudios de género en la historia han observado los procesos e instituciones que han dividido los espacios en productivo y reproductivo, legitimando tanto la distribución de roles como de poderes en la sociedad. Desde aquellas primeras mujeres ilustradas del siglo $\mathrm{XVIII}$ que abogaron por la igualdad, se han desarrollado posiciones que coinciden en juzgar el sesgo cultural que muestra al sexo masculino como el poseedor natural de los derechos humanos y políticos por excelencia. Describir la oposición entre los espacios público y privado es pertinente para localizar los rasgos que presentaba en el siglo XIX y observar la permanencia de estereotipos, las modificaciones de algunos roles y, sobre todo, su feroz defensa que se traslució en los códigos, manuales de conducta, prensa y literatura.

De acuerdo con Gabriela Cano y Dora Barrancos (2006), el siglo XIX latinoamericano con frecuencia se ha descrito como un tiempo de avances y emancipación de las mujeres, aunque las interpretaciones revisionistas han demostrado que, con el auge del liberalismo, perdieron privilegios y protecciones que les otorgaba la legislación colonial. Aunado a esto, las últimas décadas del siglo XIX y primeros años del XX, en México, no puede entenderse como un parteaguas en la historia de la civilidad, sino como un paulatino avance del pensamiento ilustrado que llega como una oleada de razón hacia América. Si bien los beneficios de las ideas del racionalismo y progreso dieron sonados avances a las sociedades, no podemos dejar de documentar los impactos "no tan bondadosos" que tuvieron en la vida de las mujeres.

Mientras que, en España, según Franco Rubio, los movimientos por la emancipación, así como los derechos políticos y civiles, se mantuvieron limitados pero permanentes, en contraste con la polémica alcanzada en Francia o Inglaterra (Gloria FRANCO RUBIO, 2004, p. 456). Esto se debió sobre todo a la baja incorporación de las mujeres españolas al mercado laboral industrializado, así como la persistencia del analfabetismo. La Ley de Instrucción Pública que garantiza la educación primaria de niños y niñas en las escuelas estatales con separación de sexos se promulgó en 1857, y la lglesia católica continuó con el control de la formación de las niñas tanto de manera formal como informal durante mucho tiempo.

No obstante, en algunas ciudades, las mujeres españolas se atrevieron a publicar su opinión. Para Blasina Cantizano Márquez (2004, p. 286), en La Pensadora Gaditana (1763-1764), en 1763, inicia la tradición periodística femenina en Andalucía, dado que en Cádiz existió un ambiente propicio para movimientos artísticos o ideológicos que acogieron la defensa de los derechos de las mujeres, como el Krausismo y la Institución Libre de Enseñanza. De acuerdo ${ }^{1}$ BY. El Telegrama. Diario el más barato y noticioso. n. 356. 1890. 
a Giuliana Di Febo (1976), este hecho puede considerarse como un parteaguas en el debate feminista español, porque sus postulados sostenían la relación igualitaria y armónica entre ambos sexos, que se conseguiría a través de la libre elección del esposo/a y el respeto sincero entre ambos. Lo que ahora nos puede parecer acotado era revolucionario para un tiempo en el que, en el seno de la burguesía e incluso para las clases populares, los matrimonios eran consensuados por los padres y era inaceptable su disolución.

Para centrarnos en nuestro objetivo, proponemos hacer una revisión historiográfica sobre las formas en la que se han estudiado a las mujeres en la prensa. Estos estudios pueden agruparse en dos apartados con los que se estructura el discurso de la presente investigación. Una primera parte, en la que se aborda aquello que se dice de las mujeres en ámbito periodístico tanto en lo referente a las normas de conducta o urbanidad, creadas para modelar su comportamiento en el seno del hogar doméstico, como lo atinente al seguimiento de los crímenes cometidos contra y por ellas mismas; y una segunda parte, versada en la literatura femenina, cuyas variantes son más que manifiestas tanto en forma como en contenido. Este recorrido pone atención a la producción de los mensajes, a la posición que guardan los actores que los emiten, y al diálogo que establecen con las instituciones, generando una opinión pública.

\section{Lo que se dice para ellas: buena conducta y urbanidad}

A lo largo del período decimonónico podemos reconocer tensiones entre distintas dicotomías, como naturaleza/civilización, mujer/hombre y deseo/razón. Este fenómeno se da en un proceso inicial de instalación de principios ilustrados para luego pasar a otros románticos y terminar con preceptos de marcada índole positivista. Y ocurren como un aprendizaje sistemático. En México, durante la época novohispana, había una distancia por castas. En el siglo XIX, la distancia debía reconocerse a partir del menor o mayor grado de civilidad alcanzado, mientras que, en España, por un lado, existía el principio de igualdad ante la ley y por otro, se imponía el criterio económico como definitivo en la división social. Un fenómeno semejante fue estudiado por Norbert Elías (1996) en lo que denomina la distancia entre la nobleza urbana y la nobleza rural producida en Francia en la última década del siglo XVI y primera del siglo XVII:

Se trata sobre todo de hombres que se han convertido en una aristocracia gran-cortesana [...] La reforzada coacción para la autocoacción les abre nuevas alegrías y placeres, nuevos enriquecimientos y refinamientos - en una palabra, nuevos valores, junto con nuevas angustias y peligros.

La específica urbanidad cortesana que se basa en las autocoacciones convertidas en una segunda naturaleza, forma parte de aquello que distingue a los cortesanos aristócratas de todos los demás, lo que les da, según su propio sentir, una ventaja sobre éstos. Precisamente por ello, las autocoacciones son inevitables. (Norbert ELIAS, 1996, p. 319)

Siguiendo con Elías, conceptos como alienación o romanticismo no pueden entenderse si no comprendemos la forma en que se desarrollaron los aparatos específicos de autocoacción - lo que también denomina un enmascaramiento aprendido autoconsciente, pero esta capacidad sostiene que sólo es posible "en sociedades cuya estructura específica exige un enmascaramiento relativamente elevado, estable y uniforme de los impulsos emocionales momentáneos, como medio para sobrevivir y tener éxito socialmente, como una peculiaridad integral de la estructura de la personalidad" (p. 318). La aprehensión de estas conductas y su estimación fueron ampliamente utilizadas en las cortes y extendidas de algún modo a la burguesía. Sin embargo, estos usos no fueron indispensables para otras capas de la sociedad, donde la gente se ganaba la vida trabajando, por lo que su ausencia se convirtió en un rasgo característico de su propia identidad.

Empero, ¿qué repercusiones tenía este aprendizaje en la vida de las mujeres? Pudiera pensarse que estaban en desventaja, pero una buena estrategia para superar la marginalidad fue aprender y dominar en mayor medida los artilugios de la urbanidad. Indica Elías (1996, p. 322) que no sólo las máscaras, sino también los abanicos, son un símbolo de su disfrazamiento. Y en ese sentido, las mujeres, al permanecer más tiempo en la corte, acrecentaron con mayor eficacia sus tácticas, logrando un gran poder. Algo semejante sucedió con las mujeres en el México del siglo XIX que, en ausencia de sus maridos por cargos militares o civiles, se quedaban a cargo de los negocios de la casa o la finca, logrando un gran reconocimiento en el manejo de la economía familiar.

¿Y cómo se puede justificar que mientras sucede un abandono de la naturaleza con las conductas civilizadas, la explicación de la inferioridad femenina recae nuevamente en su naturalización? Para el último tercio del siglo XIX comienzan a expresarse opiniones acerca de lo que eran y, sobre todo, lo que debían ser las mujeres en el marco del orden y el progreso. Ramos Escandón observa que la idea positiva es que la evolución ocurre de acuerdo con leyes naturales, donde la intervención humana individual es casi nula y respecto a las mujeres: 
[...] hay un intento de establecer una "nueva mujer", la mujer positiva. Lo novedoso del concepto de mujer consiste en admitir su incorporación, limitada, a la fuerza de trabajo, pero sin cuestionar ni modificar su papel en la familia; más bien indaga y abunda sobre la importancia del papel de la maternidad y de las obligaciones de la esposa. (Carmen RAMOS ESCANDÓN, 2001, p. 295-296)

De esta prerrogativa surgen abundantes manuales de conducta, buenas costumbres, se editan revistas para mujeres y artículos de entretenimiento que la mayoría de las ocasiones son escritas por hombres. Estos discursos y pautas inundan la prensa al mismo tiempo que se permeabilizan en leyes y escritos de los principales ideólogos de la época.

Así, para Yucatán, Miranda Ojeda hace el cómputo de las ediciones y reediciones de manuales de buenas costumbres y obras a lo largo del período decimonónico y primera década de la pasada centuria. Además, señala que el Manual de buenas costumbres y urbanidad, escrito por el venezolano Manuel Antonio Carreño (1812-1874) en 1853, se vendía en Mérida desde diciembre de 1873 en la Librería Meridiana (Pedro MIRANDA OJEDA, 2007, p. 151). Este manual ha sido estudiado por el impacto que tuvo en el disciplinamiento de las conductas urbanas, sobre todo la aprehensión que hicieron las mujeres de sus consejos (Valentina TORRES SEPTIÉN, 2001). El aumento de la circulación de esta literatura de mediados del siglo está en concordancia con la instalación del pensamiento positivo para ceñir a la capital yucateca a los cánones que se dictaban desde la capital. Aunque ha de comprenderse que muchas de estas ideas llegaban de primera mano gracias al flujo migratorio entre Europa y la Península. En España, algunos de estos manuales fueron las Lecciones de moral, virtud y urbanidad de José de Urcullu (1770-1852) (editados de 1826 a 1897), el Tratado completo de urbanidad en verso para uso de los jóvenes de José Codina (1867-1934) (de 1838 a 1925), la Urbanidad en verso para uso de las niñas de José Codina (de 1860 a 1901), La niña cortés o lecciones de urbanidad y decoro del mismo Codina (1863-1917), entre otros (Jean-Louis GUEREÑA, 2012, p. 245-246). Véase que eran muchos los manuales consagrados al colectivo femenino, cuyo comportamiento, conforme a los criterios morales de las mentalidades biempensantes, resultaba clave para la pervivencia del sistema patrimonial.

En el caso de Mérida, la prensa tenía preparadas sus propias reglas de conducta sobre aquellos asuntos que preocupaban al colectivo masculino. Hombres que, con posibilidades económicas y poder para publicar, estaban inmersos en una red de circulación de su pensamiento, dedicados a la política o funcionarios públicos. El periódico mexicano El Telegrama, con el lema "Diario el más barato y noticioso", con el costo de un centavo el ejemplar o medio real a la semana, propiedad de un abogado que ejercía como representante del Ministerio Público en 1896, señalaba tener especial cuidado de tratar sólo las cuestiones de interés palpitante que atañían directamente a la sociedad. Además, el periódico transmitía con frecuencia expresiones que llamaban a las mujeres yucatecas, sobre todo a las más jóvenes, a dejar de entusiasmarse por las modas extranjeras que provocaban confusión en el vestir, pensar y hablar en ese momento. Estas notas, firmadas a veces por "Ángela", otras por "El amigo de la Verdad", casi siempre figuraban en la primera plana. Esto debe considerarse con atención porque indica una posición privilegiada para la compra del periódico, generando cierta polémica con los lectores, que iba más allá de los cuestionamientos políticos y religiosos. Así, un texto titulado "Solteros y solteras" hace referencia a una escritora llamada María Vicens para argumentar que eran las mujeres quienes tenían la culpa de la soltería de muchos hombres. Esto se debía a que el colectivo masculino imaginaba hallar en el seno de su hogar "una mujer bien educada pero no bachillera, una mujer económica y sencilla de costumbres que con pocos medios supiera - cómo gobernar una casa y no se - perdiera - en exterioridades, en una palabra, una mujer capaz de hacer feliz a un hombre". ${ }^{2}$ La virtud alterocentrista otorgada a las mujeres se exacerbaba hasta llegar incluso a anular su voluntad, reduciéndolas a un estado de servitud que las alejaba del plenilunio de su libertad como individuo de pleno derecho.

Después de la revisión de los números de este diario, en algunos más, en mayor o menor medida relacionados con el tema del presente apartado, puede observarse que aparecen notas sobre la condición de los jueces de paz, el sistema de justicia o el plan de estudios de la escuela de jurisprudencia. He ahí por lo que puede considerarse que en este periódico participaban abogados, letrados, incluso estudiantes de jurisprudencia y jóvenes en edad casadera que podían redactar artículos como el de "A los enamorados", 3 que proporcionaba consejos a los varones que pensaban contraer matrimonio basándose en entrevistas a mujeres jóvenes y viudas.

Otro tema semejante aparece en el artículo "La mujer sarcástica", donde pueden leerse sentencias como la que seguidamente reproducimos: "Huye de una mujer sarcástica como de una enfermedad contagiosa", "estas mujeres se alaban de poseer lo que ellas llaman "viveza" o "ningún hombre puede estar seguro de sí mismo en su presencia", insistiendo en la idea de

${ }^{2}$ BY. El Telegrama. Diario el más barato y noticioso. Mérida, Yucatán. 11 de diciembre de 1890. $2^{a}$ Época. Núm. 540.

${ }^{3}$ BY. El Telegrama. Diario el más barato y noticioso. Mérida, Yucatán, 18 de junio de 1890. $2^{a}$ Epoca, n. 462 
que lo que en la niñez puede ser "picante" y "divertido", más adelante se convierte en rudeza y agresividad. En ese mismo sentido, se advierte en El Telegrama esta noción de "sarcasmo" atribuido al colectivo femenino, con las frases, "la mujer no puede degenerar en este siglo que le pertenece y es ella quien debe mostrar a los niños que la verdadera política y la etiqueta proceden del corazón, no de la cabeza"; o, "la mujer querida por su propio sexo y admirada y respetada por los hombres, no es por ningún concepto sarcástica". ${ }^{4}$ La ironía mordaz y cruel que se atribuía a las mujeres se erigía como maltrato y ofensa hacia los hombres.

Volviendo al tema de la moda, encontramos un ejemplo más de la importancia que se le concedía en el periódico mexicano El corcovo (1879-1880) con el encabezado "La mujer"5 que, abarcando toda su primera plana, se preocupa por el comportamiento femenino, en ese momento, enajenado con la moda europea. Estos condicionantes eran reforzados en los espacios de convivencia, como las tertulias, la plaza o la Iglesia, y vigilados con empeño por las autoridades judiciales como se expondrá más adelante. Aunado a esto, la institución eclesiástica continuaba teniendo un papel importante en la comprensión del mundo y el seguimiento de la moral, permeando todas las capas de la población e incluso a las autoridades civiles que debían seguir la división liberal entre Iglesia y Estado.

En España, por su parte, la inferioridad femenina era un concepto generalizado y razonado por las más diversas y disparatadas explicaciones, mostrándose éstas, a su vez, en la prensa de acuerdo a lo estudiado por Blasina Canziano, quien clasifica a la prensa femenina decimonónica en dos grandes grupos: una sin ideología política o social, que se dirige a la "mujer tradicional" para reforzar su estatus de madre y esposa; y otra, con inclinación feminista que reivindicaba la participación del colectivo femenino en distintos campos. Canziano señala que hubo autoras constantes como Ángela Grassi (1823-1883), Carolina Coronado (1820-1911), Gertrudis Gómez de Avellaneda (1814-1873), Cecilia Böhl de Faber (1796-1877) —esta última siempre firmó con el nombre masculino de Fernán Caballero, seudónimo que adopta esta ilustre autora española para poder formar parte del misógino ambiente literario de la época. Aunque la mayoría de estas autoras mantenían en sus escritos "apuntes de belleza, trucos del hogar, consejos para destacar, horóscopos, normas de conducta" (CANZIANO, 2004, p. 294), contrastaban dichos contenidos con los que actualmente aparecen sobre cuestiones laborales, de psicología, derecho, cuerpo femenino o el sexo sin tapujos.

Avanzándonos en el tiempo, en una comparativa entre los ámbitos aquí tratados, observamos cómo los resultados anteriores coinciden con lo estudiado por Herrero Faúndez al comparar la imagen de la mujer en la prensa entre los periodos de 1910-1915 y 2000-2005, en los periódicos $A B C$ y Socialista y, $A B C$ y El País. En sus resultados muestra un porcentaje muy alto de noticias que identifican a las mujeres como seres supeditados al varón o bien como posesión de éste (Rocío, HERRERO FAÚNDEZ, 2010, p. 595). Asimismo, en lo relativo al tema de la violencia, y particularmente en el primer periodo, las mujeres son presentadas como víctimas, culpables/ provocadoras, pobres, infelices, tristes e indefensas; mientras que, para el segundo, a su imagen se le suma el ser valientes/comprometidas, enamoradas (del agresor), objeto de debate político, necesitadas de protección social y de leyes que las protejan y abran posibilidades, o consentidoras de los agravios en su contra. Agregar nuevas formas de percepción de violencia coincide con el avance de los derechos de las mujeres y puede ser que, con cierta conciencia adquirida por los medios sobre el impacto que tiene su tratamiento, se otorgue a la violencia para legitimar las agresiones o censurarlas. Esto es aún más visible en la prensa y la literatura sobre crímenes como los que a continuación se revisa.

\section{Lo que se escribía sobre las criminales y criminalizadas}

Un tema en el que coinciden con suficiente evidencia la prensa y literatura del periodo en revisión, tanto en México como en España, es en el gusto por las descripciones cargadas de emoción y detalle que se ofrecían en las comandancias de policía o juzgado que después se transformaban en melodramas, folletines, o novelas por entregas que exaltaban los peligros de las calles, los lugares y los espacios en los que se conjuntaban las malas conductas de hombres y mujeres, así como la diferenciación en el tratamiento de acuerdo al sexo del agresor o la víctima, los antecedentes del delito y, en numerosas ocasiones, la valoración moral que se hacía del mismo. Lisette Rivera Reynaldos (2016) distingue entre mujeres criminales que cometieron un acto criminal, y las que fueron señaladas como causa de este, en algún nivel de complicidad, es decir criminalizadas. Las primeras pueden ceñirse a lo que contienen los expedientes judiciales, los testimonios, peritajes médicos, incluso la propia confesión, entretanto, las criminalizadas se producen al emitir juicios sobre los valores o comportamientos ideales de las mujeres respecto al hecho delictivo.

\footnotetext{
${ }^{4}$ BY. El Telegrama. Diario el más barato y noticioso. Mérida, Yucatán, 6 de abril de 1891. $2^{a}$ Epoca, n. 717

${ }^{5}$ BY. El Corcovo. Mérida, Yucatán, 23 de mayo de 1879. Año 1, n. 6.
} 
En este apartado, tomamos dicha distinción para observar lo ocurrido en la prensa y literatura porque no bastaba mostrar a las criminales, sino criminalizar las conductas que consideraban inmorales para las mujeres. Un buen número de notas periodísticas, insumo para la literatura, provenían de los denominados crímenes pasionales que, si bien no se encontraban tipificados de esa forma en la codificación penal de la época, sí eran identificados como tales en el lenguaje coloquial de la población. Se distinguen de otros homicidios por los elementos que lo constituyen, los cuales implican, en primera instancia, de acuerdo con Rivera Reynaldos, "la existencia de un vínculo amoroso -previo o existente al momento de cometerse el delitoentre el agresor y víctima así como la ruptura violenta de dicho vínculo" (2016, p. 346). Estos crímenes pasionales o amores trágicos provocaban la atención del público, que los seguía en diferentes formatos hasta su desenlace. Podría enfatizarse el hecho de que un suceso de violencia doméstica o que sucedía en la intimidad, de un momento a otro se ventilaba en el público, que parecía disfrutar con la pena ajena.

¿Qué podemos saber de una sociedad a través de la violencia que transita de la prensa hacia la literatura y viceversa? ¿Qué repercusiones tiene en la forma en la que se juzga el suceso y los comportamientos permitidos? Si bien se pueden matizar estas preguntas y pensar también en los artilugios de persuasión que implementaban los medios impresos para llamar la atención sobre sus publicaciones, como el formato breve y por entregas para mantener el suspenso, también contribuyeron en el uso de ilustraciones o fotografías, los colores tanto de papel como de la tinta en la que se imprimían y el énfasis en un lenguaje melodramático, lleno de adjetivos. Esto no impide reflexionar sobre el gusto o el placer por este tipo de narraciones y la ética de sus consumidores/as.

Gabriela Pulido Llano (2016, p. 153) identifica a la nota roja, género sensacionalista que surge a principios del siglo XX, en México, como un espacio donde se ponían en conflicto el gozo y el daño, las pulsiones de atracción y repulsión, Eros y Tánatos. En España, el equivalente a esta "nota roja" fueron las "crónicas de sucesos" en las que cristalizaba este fenómeno. Más tarde también existieron formatos como historietas del Magazine de Policía (1939-1969), que expusieron el dibujo de corte realista con énfasis en los gestos, claroscuros, textos al pie del cuadro y que terminaban esbozando alguna moraleja. ${ }^{6}$ Argumenta que eventos asociados a la prostitución pudieron influenciar el rumbo de políticas públicas y tuvieron impacto en la vida nocturna de la capital de México, porque las notas no constituían reclamos para mejorar la condición de las meretrices, al contrario, se mantenía la estigmatización y se extendía a las mujeres que trabajaban en cabarets y salones de baile como meseras, cocineras o bailarinas.

Respecto a la relación entre los eventos dignos de relevancia mediática con las sentencias judiciales, Elisa Speckman (2014) observa que algunos crímenes son juzgados duramente en la prensa escrita de México, mientras las resoluciones judiciales atienden estrictamente a la letra de la ley. En su estudio admite que con frecuencia sucedían dos formas de transgresión: la social y la penal. Así, la transgresión social consistía en no cumplir con el estereotipo del ser femenino de sumisión, recato, inocencia y pasividad; mientras que la transgresión penal podría incluir una mayor pena en función de que el delito lo cometiera una trabajadora sexual o una disminución si se trataba de una buena mujer que delinquió con el ánimo de conservar el honor de los hombres de su familia. En cambio, Piccato, al seguir el caso de una joven que asesina a un senador por vengar la muerte de su padre, encuentra que las representaciones narrativas y las nociones sobre el honor de las mujeres en la prensa sí impactó a la justicia e incluso la ayudó a evadir el castigo (Pablo PICCATO, 2012). La reflexión se mantiene vigente a partir del análisis de diferentes discursos en la construcción de un sistema de género a finales del siglo XIX.

En comparación, en España puede observarse el mismo entusiasmo por trasladar los crímenes pasionales a la literatura, puesto que eran muchos los hombres que sentían placer al leer los crímenes que se cometían contra las mujeres en la prensa escrita del momento. A este fenómeno se le dio el nombre de neronismo, donde la violencia acaecida en el ámbito privado se permeabilizaba en el público para deleite de sus asiduos consumidores. Esta violencia no estaba "visibilizada" porque lo que se "veía" era concebido como algo "normal" dentro del ámbito doméstico, privado e íntimo, por lo que, en esas condiciones, una posible denuncia carecía de valor (Jordi LUENGO LÓPEZ, 2011 , p. 57). Del fenómeno del neronismo se habló en los albores del pasado siglo, pero no se volvió a mencionar en las décadas siguientes, pese a las evidentes muestras de su existencia.

Otra característica es el aspecto lúdico otorgado a la categoría estética que estableció en torno a la dualidad mujer santa/mujer pérfida. El relato oscilaba con frecuencia juzgando la bondad y la belleza frente a la amenaza y el castigo, pero ¿quiénes demandaban estos escritos? Tanto para México como para España encontramos el consenso de que estos textos formulados desde los letrados o burgueses se dirigían a una población popular y con deficiente educación moral, cabría preguntarse qué carencia pesaba más, si la económica o la material. Aunado a esto, se agrega la diferencia en el tratamiento formulado desde la prensa o desde la literatura.

- En España, este fenómeno acontecía también en publicaciones análogas a la mexicana Magazine de Policía, siendo la más conocida la de Museo criminal (1904-1909). 
Speckman encuentra que periódicos y revistas policiales condenaban de forma severa los crímenes, al contrario de los textos narrativos. Éstos mostraban una mayor comprensión hacia los homicidas pasionales y sobre todo si estos eran hombres, pues a las criminales se les condenaba cuando mataban o cuando eran víctimas que mostraban indicios de infidelidad o rompían con el modelo de conducta aceptado (SPECKMAN, 2014, p. 178). Con todo, al menos en el caso español, esta desequilibrada imputación del vilipendio gratuito hacia las "criminales" no implica que en el ámbito literario se defendieran a las mujeres acusadas de homicidio, como fue el sonado caso del crimen de la madrileña calle de Fuencarral. Acaecido en 1888, este crimen anciliario fue muy conocido en toda España, en tanto que la inculpada, Higinia Balaguer, fue sentenciada a muerte por haber asesinado a la mujer para la que trabajaba, Luciana Borcino, cuando, en realidad, había sido el hijo de ésta (LUENGO LÓPEZ, 2017, p. 94-95).

\section{Lo que decían de sí mismas}

Al igual que en España, en México son numerosas las publicaciones que pretendían conducir a las mujeres hacia el ideal burgués femenino. En su mayoría eran escritas por hombres y en menor medida por mujeres, que podían elegir entre firmar con su nombre y apellido de su marido, con iniciales, o utilizar como seudónimos nombres masculinos. Clara evidencia de este fenómeno fue María de la O Lejárraga, quien escribió durante mucho tiempo con el nombre de su marido, Gregorio Martínez Sierra, incluso después de su separación (LUENGO LÓPEZ, 2016). En México, Ana Ivonne Díaz (2000, p. 111) ha documentado como las primeras escritoras del siglo XIX participaban bajo pseudónimos para ocultar su identidad.

En este apartado haremos una breve mención de las escritoras, pero profundizaremos en los textos que van separándose de ese esquema, que toman algunos riesgos y que pueden considerarse textos emancipadores sirviendo de ejemplo para las mujeres de las décadas siguientes.

En México se inauguran las revistas escritas por mujeres con La Siempreviva (1870-1872), que fue un proyecto editorial que incluía una escuela para mujeres y una sociedad literaria. La revista es considerada la primera publicación escrita exclusivamente por mujeres, que comenzó su circulación en 1870 a 1872, en un tiempo en el que aún no era obligatoria la educación primaria para las niñas. Apuntan Celia Rosado Avilés y Óscar Ortega Arango que el proyecto se inscribe en el marco de la secularización de la educación en México, pues existe una tensión entre la ética burguesa y romántica de las mujeres y la incorporación como individuos o ciudadanas (ROSADO AVILÉS; ORTEGA ARANGO, 2009). Tiene un claro sustrato socialista y, en muchos escritos, una notoria influencia religiosa, lo cual era contrario a lo que solicitaban sus patrocinadores estatales. Pero ¿quiénes leían La Siempreviva? Desafortunadamente, no se cuenta con la lista de suscriptores, pero existen constantes diálogos con la intelectualidad masculina de la época y constituye un esfuerzo verdadero por transgredir los roles asignados, a la vez que salvaguarda la posibilidad de emisión del discurso.

De las escritoras de este siglo se puede afirmar que incursionaban a contracorriente. El pensamiento de que la educación era un medio para la participación activa de las mujeres permeaba entre quienes habían tenido el privilegio de la educación por su condición de clase, y lentamente fue extendiéndose a jóvenes de otras clases sociales a través de la obligación estatal de la educación primaria. De acuerdo con González Rey, en Yucatán, existió una Escuela Normal para profesores varones de 1868 a 1873 y fue hasta 1881 , mediante un decreto del gobernador Manuel Romero Ancona, que se constituyó un establecimiento permanente para profesores de primaria:

En esta escuela se aceptaría un estudiante por cada Partido del Estado "que sea notoriamente pobre", quien seguía un programa de estudios de cuatro años de duración que incluía áreas de aritmética práctica y razonada, gramática, retórica, caligrafía, declamación, moral, calistenia, higiene, geografía universal y patria, historia de México, de Yucatán; nociones generales sobre las ciencias y derecho público constitucional y pedagogía. (Diana Crucelly GONZÁLES REY, 2014, p. 94)

En cambio, el Instituto Literario de Niñas como espacio de formación de profesorado femenino comenzó a funcionar mucho antes, en 1877, bajo la tutela de la profesora Rita Cetina (1846-1908). En el Instituto preparaba al profesorado para primaria o segundaria y las estudiantes podían tener una beca. Era tal su importancia, que de 1867 a 1892 tuvo 6.000 estudiantes. Este proyecto formativo era parte de la sociedad literaria La Siempreviva, dirigida por las maestras y poetisas Rita Cetina, Gertrudis Tenorio Zavala (1844-1926) y Cristina Farfán (1846-1922) bajo el lema "Bellas Artes, llustración, Recreo, Caridad" (GONZÁLEZ REY, 2014, p. 94). De acuerdo con Piedad Peniche (2015, p. 31), la profesora Rita creó en Mérida una sociedad literaria que editó la primera revista escrita exclusivamente por mujeres en México, y bajo el mismo nombre contenía tres instituciones: sociedad, revista y escuelas de bellas artes para señoritas de la clase alta, de pago, y otra de enseñanza de primeras letras, gratuita para niñas pobres. 
De la lectura de la revista se desprende un discurso moral y religioso coincidente con las costumbres de la época, abogando por una maternidad patriótica y la participación de las profesoras en su empeño formativo. Cabe reconocer que este ejercicio de escritura y su circulación en el ambiente político de la época fue revolucionario, formando a mujeres que más adelante insistirían en la emancipación política y económica del colectivo femenino. En la siguiente estrofa de la profesora Rita explica el lugar privado de las mujeres y su función en la sociedad:

Acaso por ser ésta la última obra de sus manos infundió en ella un alma débil y sensible. Sin embargo, le dio para ejercer sobre la tierra una misión bastante delicada. La crió para compañera del hombre, para ser un consuelo en las adversidades de la vida y alimentar la paz y la tranquilidad en el hogar doméstico.

Más todavía. La mujer ha sido destinada por la Omnipotencia para formar el corazón del hombre, es decir, para infundir en él los sentimientos de religión, virtud, honradez y dignidad. (Rita CETINA GUTIÉRREZ, 1870b, p. 1)

Siguiendo con el estudio de Peniche, para su tiempo las profesoras Rita y Gertrudis vivieron una vida de intelectuales, solteras y liberales, ya que "se mantenían a sí mismas, lo que contrastaba en el contexto sociopolítico de sus tiempos, cuando en Yucatán no existían las condiciones de creación de conciencia feminista" (PENICHE, 2015, p. 33). En un texto que se titula "La mujer del siglo actual", profesora Cetina reflexiona sobre una nota periodística que señalaba la titulación de 300 o 400 doctoras en Estados Unidos ${ }^{7}$ y las posibilidades que tendrían las mujeres de contribuir al engrandecimiento de México y la Península yucateca a través de su educación:

Pero el siglo XIX tendiéndole con cariño una mano protectora, la levanta de la postración en que yaciera tanto tiempo y la conduce al dintel de los establecimientos de enseñanza que ha preparado para ella y a donde penetra sonriendo de felicidad, á saciar su sed de instrucción en las bienhechoras aguas del saber. (CETINA RODRÍGUEZ, 1870a, p.1)

Aunado a su quehacer como formadoras, estas mujeres intervenían en política a través de su lenguaje poético y promotoras en actividades de caridad. Georgina Rosado Rosado apunta que quizá su mayor logro haya sido que las familias de la época, seguramente tradicionales, les confiaran la educación de sus hijas "lo que implicó tener que reproducir estereotipos e impartir conocimientos y habilidades para convertirlas en buenas amas de casa y madres, pero sin dejar de cumplir el objetivo de garantizar la participación de las mujeres en la educación científica y la vida política" (Georgina ROSADO ROSADO, 2010, p. XV). Al respecto, Peniche (2015, p. 72) concluye que es muy probable que las integrantes de la Sociedad se hayan enfrentado a diferentes obstáculos y estuviesen en medio de tensiones derivadas de las ideas patriarcales. En otros espacios, pero en la misma época, Josefa Martín Díaz (2014) analiza las experiencias de mujeres misioneras que se introdujeron al mundo católico en el sureste para fundar iglesias protestantes de distintas denominaciones. Mujeres provenientes en su mayoría de otros estados del país llegaron a Yucatán en compañía de sus familias con un fin religioso que no se distanciaba tampoco de las ideas de progreso de la época, al contrario, contribuía al debilitamiento de la Iglesia católica. Asumieron un rol más allá de ser esposas, madres o hijas de los pastores o ministros y a partir de la concepción bíblica del cuerpo guiaron programas de educación, salud, nutrición e higiene. Además, participaron en el proselitismo religioso, tejieron alianzas con otras denominaciones para sobrevivir y, como Las Siemprevivas escribían sobre el papel de las mujeres en órganos literarios, como El abogado cristiano ilustrado (Metodista) $(1878,1889-1891$ ) y El Faro (presbiteriano) (inicio en 1885 y existen registros hasta 1937).

De forma casi simultánea, aparecen en la capital del país publicaciones escritas por mujeres con secciones de literatura, aspectos históricos, poesía, carteleras de espectáculos como Las hijas de Anáhuac, en 1873, con cuatro meses en circulación, El álbum de la mujer de 1883-1890, que incluía crónicas de eventos sociales ocurridos en México, Madrid y París, y una sección de modas. Por su parte, El correo de las señoras, del cual asumió su dirección la viuda del redactor principal, con la mayor duración, de 1883 a 1893. También, antes de finalizar el siglo, surge Violetas de Anáhuac de 1887-1889, que destaca por tener un número considerable de colaboradoras y abarcar temas de política, educación, así como de todos aquellos temas que el discurso dominante atribuía a las mujeres (Elvia HERNÁNDEZ CARBALLIDO, 2012).

Siguiendo con nuestra comparación, encontramos que, en España, se distingue una prensa dirigida a las mujeres con una marcada temática: la feminidad normativa, pero se inician casi un siglo antes que en México. El estudio de Menéndez y Figueras muestra que existió un trinomio belleza-amor-hogar concebido como un sistema cerrado con elementos interrelacionados e indisolubles (María Isabel MENÉNDEZ MENÉNDEZ; Mónica FIGUERAS MAZ,

7 Se refiere a la primera escuela superior de artes liberales privada para mujeres fundada en Estados Unidos de Norteamérica por Mateo Vassar en 1861 (Oficina de Programas de Información, 2006). 
2013, p. 32). En esta época pueden encontrarse varios textos en los que se ensalzan los distintos movimientos sufragistas que estaban acontenciendo, como los de La Pensadora Gaditana, revista editaba en Madrid y en Cádiz, de marcado carácter feminista. En ella son frecuentes las columnas firmadas por mujeres, aunque, a pesar de ello y de su contenido, la publicación no es considerada como prensa femenina. Un parecer que no deja de ser del todo falso, porque el objetivo de La Pensadora, en realidad, era hacer frente a los ataques antifeministas de José Clavijo y Fajardo (1726-1806), publicados en El Pensador Metritense (1762-1766).

Otra publicación es El Periódico de las Damas fundado en 1822, en Madrid, que fue el primero en su tipo editado en España porque se dedicaba sobre todo a la moda, además de algunos consejos sobre belleza e higiene, acertijos y distracciones en prosa y verso. De igual modo, coinciden nuestras circunstancias con las numerosas publicaciones escritas por hombres dirigidas a mujeres con una voluntad moralizante. Así, hacia 1880, aparecieron 18 publicaciones de diversos temas, entre los que figuraban la moda, la religión y sobre la condición de las mujeres y de higiene en general. Hasta 1882, en España, se editan revistas feministas como Ellas (1851) o La Mujer (1882), llevando esta última por subtítulo "Periódico científico, artístico y literario sobre la condición femenina", lo cual la ha llevado a ser considerada como una de las más radicales del período decimonónico, tanto por su contenido como por la terminología utilizada, puesto que no se dirige a la mujer sólo como madre (MENÉNDEZ MENÉNDEZ; FIGUERAS MAZ, 2013, p. 34-35).

En México, el registro biográfico de las escritoras del siglo XIX comienza su revisión historiográfica y muestra que gran parte de ellas pertenecieron a la clase media y debían cumplir con sus funciones matrimoniales y ser portavoces de la familia cristiana para poder hacerse perdonar "la falta" de escribir. En su mayoría eran autodidactas, pero pocas van a pugnar por la instrucción de las mujeres. La motivación para la escritura fue la muerte de algún hijo o del esposo y porque en las ciudades pequeñas se veía bien que las señoras de la sociedad culta escribieran pequeños poemas dedicados a sus parientes. En España, sin embargo, no tuvieron mucho campo las escritoras rebeldes, que acabaron en la cárcel o en el destierro, aunque sí pesó la opinión de las pedagogas y médicas porque fueron quienes denunciaron la situación de las mujeres y la necesidad de instrucción. Con todo, se trasluce en los escritos de estas mujeres una manifiesta crítica a su propia condición, como lo muestra en su estudio Simón Palmer, cuando cita a Rosalía de Castro (1837-1885): "Sólo cantos de independencia y libertad han balbucido mis labios, aunque alrededor hubiese sentido, desde la cuna ya, el ruido de las cadenas que debían aprisionarme para siempre, porque el patrimonio de la mujer son los grillos de la esclavitud" (María del Carmen SIMÓN PALMER, 1982, p. 483). Sin duda, una imagen algo desalentadora del desarrollo de las mujeres en esa línea evolutiva del devenir histórico.

Pueden localizarse perspectivas ambivalentes sobre lo que sucedía en otras partes de Europa e incluso de América. Mientras Sofía Casanova (1861-1958), en 1913, decía que era escandaloso lo que acontecía en Alemania sobre la idea de ser madres sin matrimonio, sin contar con lo que pasaba en la América (1982, p. 484), escritoras como Emilia Serrano (1843-1922), Baronesa de Wilson, a finales del siglo XIX, escribe libros sobre sus viajes a América recorriéndola de Canadá a la Patagonia, con una versión del panhispanismo contribuyendo a mejorar la imagen de la relación entre las excolonias y España. Asimismo, en su mensaje dirigido a las mujeres ésta procura contradecir la sentencia de que sus congéneres femeninos sean seres inferiores con respecto a los masculinos, aprovecha el imaginario de la modernidad católica para resaltar la participación de las mujeres en la familia y ciertas ocupaciones públicas, pero sin contradecir el ideal femenino (María Isabel MENA MORA, 2014, p. 39). Es probable que lograra desenvolverse en el espacio público con mayor avidez que otras escritoras dada su posición de noble y viuda.

En concordancia con el estilo de Serrano, para principios del siglo XX aparece el término feminista a través de la escritora catalana Dolors Monserdà (1845-1919) quien, en 1909, adoptó el término "feminista" en su libro Estudi Feminista (1909), donde rechaza las bases laicas del feminismo internacional y aboga por un reformismo católico y nacionalista de tintes conservadores, que señala el derecho a la formación académica de las mujeres (María Eugenia FERNÁNDEZ FRAILE, 2008, p. 14). Como dos líneas paralelas se observa el desarrollo de una prensa y literatura formulada por mujeres que atadas a su tradición irrumpen en la opinión pública. Como vehículo, el catolicismo, en España oficial y en México cultural, las mujeres de forma lenta, pero constante, se introdujeron en las letras, en las profesiones y en el espacio público para pugnar por el derecho a la educación como medio para lograr la movilización de la conciencia femenina y avanzar hacia la demanda de derechos civiles y políticos que terminarían de lograrse en hasta el siguiente siglo.

\section{Conclusiones}

La comparación de los elementos de la prensa dirigida hacia las mujeres y la escrita por ellas ha mostrado las funciones que cumplieron los medios impresos para establecer y 
difundir los cánones morales femeninos. Las diferencias que en ellos se detectan obedecen más a una apropiación divergente de los mismos elementos con una distancia en el tiempo, pero conservando idénticos matices en las normas impuestas - y los sobresaltos - ante las transformaciones educativas y laborales de las mujeres. Los impulsos de los movimientos sufragistas del exterior, así como las reacciones adversas que contra el mismo pueden observarse tanto en México como España, demuestran que el devenir histórico seguía su curso y que las libertades femeninas continuaban implantándose en el constructo ciudadano, aunque no con la celeridad que el colectivo femenino anhelaba. La narración de lo ocurrido en ambas naciones alcanza un gran paralelismo, sobre todo en lo relativo a la violencia generada contra las mujeres y la timorata denuncia que contra ella se hacía en la prensa escrita decimonónica.

Esto puede deberse a la comunicación constante entre las naciones y el interés de la burguesía mexicana por conducirse como los europeos, que quedaba reflejado en sus periódicos. Un deseo que no se reducía sólo al plano conductual, sino que se extrapolaba a otras manifestaciones culturales, como la urbanística de sus ciudades, con paseos llenos de flores, o la moda proveniente del Viejo Mundo, aunque paradójicamente, siempre se hizo con cierto clima de resistencia. Asimismo, la revisión de la posición de las mujeres en la prensa y la literatura muestra una férrea disciplina de las conductas, con la intensión de transformar a la población y adaptarla a un modelo de modernidad, pero manteniendo a la división del trabajo y los cánones morales. A la par, persisten carencias y diferencias sustanciales como el analfabetismo, pues no podemos olvidar que, como apunta Amelia Válcarcel (2008, p. 23), en el siglo XIX se produce un retroceso en el reconocimiento que habían logrado escalar las mujeres de clases privilegiadas durante el Antiguo Régimen. Al contrario, en este periodo, formas de pensamiento como el romanticismo exaltaron la vuelta a la naturaleza, al nacionalismo y los elementos pasionales y preconscientes. En este marco de pensamiento se tejen las primeras ideas de ciudadanía, quedando nuevamente fuera la participación política de las mujeres, pues su desigualdad era esencial para el sostenimiento de privilegios masculinos, cuya razón de ser se hallaba en un razonamiento exclusivamente biológico.

En ese marco de acción, donde las mujeres burguesas se veían abocadas a cumplir con una voluntad que debían acatar para poder identificarse con la idealidad preconcebida para ellas por el discurso dominante, la violencia no sólo adquiría un valor físico — del que también eran víctimas-, sino que se permeabilizaba también en el dolor de ver coaccionada su libertad como individuo. En la prensa escrita de España y México puede advertirse este fenómeno, el cual se extrapola de un país a otro casi como si de un calco se tratase, dándose por hecho de que dicha violencia se extendía al resto de capas sociales de la realidad ciudadana.

\section{Bibliografía}

CANO, Gabriela; Dora BARRANCOS. "Una era de transiciones. América Latina. Introducción". In: MORANT DEUSA, Isabel (coord.). Historia de las mujeres en España y América Latina. Vol. III. Madrid: Cátedra, 2006. p. 547-556.

CANTIZANO MÁRQUEZ, Blasina. "La mujer en la prensa femenina del XIX". Ámbitos. Revista Internacional de Comunicación, Sevilla, n. 11-12, p. 281-298, 2004.

CETINA GUTIÉRREZ, Rita. "La mujer". La Siempreviva, Mérida, n. 11, 1870a.

CETINA GUTIÉRREZ, Rita. "La mujer en el siglo actual”. La Siempreviva, Mérida, n. 7, $1870 b$.

DI FEBO, Giuliana. "Orígenes del debate feminista en España. La escuela krausista y la Institución Libre de Enseñanza (1870-1890)". Sistema. Revista de Ciencias Sociales, Madrid, n. 12, p. 49-82, 1976.

DÍAZ, Ana Ivonne. "El álbum de la mujer. Periodismo femenino: El primer paso hacia la modernidad y la ciudadanía". Desacatos, México, n. 3, p. 107-114, 2000.

ELIAS, Norbert. La sociedad cortesana. México: Fondo de Cultura Económica, 1996.

FERNÁNDEZ FRAILE, María Eugenia. "Historia de las mujeres en España. Historia de una conquista". La Aljaba XII, p. 11-20. 2008.

FRANCO RUBIO, Gloria. "Los orígenes del sufragismo en España”. Espacio, tiempo y forma, Madrid, v. 5, n. 16, p. 455-482. 2004.

GONZÁLEZ REY, Diana Crucelly. La educación de las Niñas en el Yucatán del Porfiriato 1870-1911. Tesis Maestría en Historia, Mérida: CIESAS, 2014. 
GUEREÑA, Jean-Louis. "El mercado de los manuales de urbanidad". In: TIANA FERRER, Alejandro. El libro escolar, reflejo de intenciones políticas e influencias pedagógicas. Madrid: UNED, 2012. p. 207-238.

HERNÁNDEZ CARBALLIDO, Elvia. "Periódicos pioneros fundados por mujeres:Las Hijas del Anáhuac, El Albúm de la mujer, El correo de las damas y Violetas del Anáhuac (1873-1889)". Derecho a Comunicar, Pachuca de Soto, n. 6 (Septiembre-Diciembre 2012), p. 1-20, 2012.

HERRERO FAÚNDEZ, Rocío. La imagen de la mujer en la prensa entre 1910-1915 y 2000-2005: Estudio comparado. Tesis doctoral. Facultad de educación, Madrid: Universidad Complutense de Madrid, 2010.

LUENGO LÓPEZ, Jordi. “'Mujeres que matan'. Crímenes ancilarios y neronismo literario en la prensa escrita de entresiglos (1885-1902)". In: ORTEGA, Marie-Linda; TURC-ZINOPOULOS (dirs.). De la violence et des femmes, Espagne, 1808-1918 [De la violencia y de las mujeres, España, 18081918]. Bruxelles: Peter Lang, 2017. p. 91-105.

LUENGO LÓPEZ, Jordi. "María de la O Lejárraga en Blanco y Negro. Columnas, cartas y calendarios en el advenimiento de la mujer moderna". Revista de Escritoras Ibéricas, Madrid, p. 121-152, 2016.

LUENGO LÓPEZ, Jordi. "El siniestro gusto literario del Neronismo. Un estudio comparativo en la producción franco-española sobre la violencia contra las mujeres". AnMal Electrónica, Málaga, n. 31 , p. 53-83, 2011.

MARTÍN DÍAZ, Josefa Guadalupe. Experiencias de las asociaciones femeniles evangélicas en el sureste de México, 1870-1960. Tesis Doctorado en Historia, Mérida: CIESAS, 2014.

MENA MORA, María Isabel. La Baronesa de Wilson en Hispanoamérica: Metáforas y un proyecto de modernidad para la mujer republicana (1874-1890). Tesis Maestría en Historia Andina, Ecuador: Universidad Andina Simón Bolívar, 2014.

MENÉNDEZ MENÉNDEZ, María Isabel; FIGUERAS MAZ, Mónica. "La evolución de la prensa femenina en España: de La Pensadora Gaditana a los blogs". Comunicació: Revista de Recerca i d'Anàlisi, Barcelona, v. 1, n. 30, p. 25-48. 2013.

MIRANDA OJEDA, Pedro. "Los manuales de buenas costumbres. Los principios de la urbanidad en la ciudad de Mérida durante el siglo XIX". Takwá, Guadalajara, n. 11-12, p. 131-155, 2007.

MORNAT, Isabelle. "La gesta de las terribles sufragistas en España". Archives ouvertes.fr, Villeurbanne, 2016. Disponible en: https://core.ac.uk/download/pdf/47309583.pdf). Acceso el: 20/08/2018.

DEPARTAMENTO DE ESTADOS DE LOS ESTADOS UNIDOS. Acerca de Estados Unidos. Mujeres con Influencia. Oficina de Programas de Información Internacional, 2006. Disponible en: https://documentop.com/mujeres-de-influencia-photos-us-department-ofstate 5a0e55221723dde825d95c33.html. Acceso el: 13/09/2018.

PENICHE, Piedad. Rita Cetina, La Siempreviva y el Instituto Literario de Niñas: Una cuna del feminismo mexicano 1846-1908. México: SEP-INEHRM, 2015.

PICCATO, Pablo. "La niña que mató un senador: feminidad esfera pública en el México posrevolucionario". Antropología. Revista Interdisciplinaria del INAH, Ciudad de México, n. 94 p. $96-114,2012$

PULIDO LLANO, Gabriela. El mapa "rojo" del pecado. Miedo y vida nocturna en la ciudad de México, 1940-1950. México: Instituto Nacional de Antropología e Historia, 2016.

RAMOS ESCANDÓN, Carmen. "Mujeres positivas. Los retos de la modernidad en las relaciones de género y la construcción del parámetro femenino en el fin de siglo mexicano, 1880-1910". In: AGOSTINI, Claudia; SPECKMAN GUERRA, Elisa (eds.). Modernidad, tradición y alteridad. La ciudad de México en el cambio de siglo (XIX-XX). Ciudad de México: UNAM, 2001. p. 291-317.

RIVERA REYNALDOS, Lisette. "Criminales, criminalizadas y delatoras. Mujeres involucradas en homicidios pasionales en Michoacán, 1900-1920”. In: SPECKMAN GUERRA, Elisa; BAILÓN VÁZQUEZ, Fabiola (eds.). Vicio, prostitución y delito. Mujeres transgresoras en los siglos XIX y XX. México: 
Instituto de Investigaciones Históricas-Universidad Nacional Autónoma de México, 2016. p. 345370.

ROSADO AVILÉS, Celia; Oscar ORTEGA ARANGO. "Tradición y transgresión en la configuración del ideal femenino en La Biblioteca de Señoritas y la Siempreviva, revistas literarias yucatecas del siglo XIX". In: MIRANDA OJEDA, Pedro; ZABALA AGUIRRE, Pilar (eds.). Normas, transgresiones. Infracciones al orden en la sociedad yucateca. Mérida: UADY, 2009. p. 101-141.

ROSADO ROSADO, Georgina. "Prólogo. Para comprender a La Siempreviva". In: CAMPOS GARCÍA, Melchor (coord.). La Siempreviva, 1870-1872: El arte de combatir por la emancipación de las mujeres. Mérida: Instituto para la Equidad de Género en Yucatán-Instituto de Cultura de Yucatán, 2010.

SIMÓN PALMER, María del Carmen. "Escritoras españolas del siglo XIX o El miedo a la marginación". Anales de Literatura Española, Alicante, n. 2, p. 477-490, 1982.

SPECKMAN GUERRA, Elisa. Del Tigre de Santa Julia, la princesa italiana y otras historias. Sistema judicial, criminalidad y justicia en la ciudad de México (siglos XIX y XX). México: UNAM. IHH. INACIPE, 2014.

TORRES SEPTIÉN, Valentina. "Manuales de Conducta, urbanidad y buenos modales durante el Porfiriato. Notas sobre el comportamiento femenino". In: AGOSTINI, Claudia; SPECKMAN GUERRA, Elisa (eds.). Modernidad, tradición y alteridad. La ciudad de México en el cambio de siglo (XIX$X X$ ). Ciudad de México: UNAM, 2001. p. 271-289.

Sara Esperanza Sanz Reyes (sara.sanz@enesmerida.unam.mx) es Doctora en Historia por el Centro de Investigaciones y Estudios Superiores en Antropología Social (CIESAS-Peninsular), Maestra en Género, Sociedad y Políticas por FLACSO-PRIGEPP- Argentina. Abogada y Antropóloga. Profesora de asignatura de la Escuela Nacional de Estudios Superiores de la Universidad Nacional Autónoma de México Consultora en temas de Educación Intercultural, Violencia de Género y Acceso a la Justicia.

Jordi Luengo López (iluengol@upo.es) es Profesor Titular en el Departamento de Filología y Traducción de la Universidad Pablo Olavide, de Sevilla. Ha recibido el XVIII Premio de Investigación Victoria Kent, el III Premio de Investigación Presen Sáez de Descatllar y el IV Premio Nacional de la Asociación Española de Investigación de Historia de las Mujeres. Entre sus publicaciones más destacadas se encuentran La otra cara de la Bohemia (2009) y Gozos y ocios de la Mujer Moderna (2008). 
COMO CITAR ESTE ARTÍCULO, DE ACUERDO CON LAS NORMAS DE LA REVISTA

SANZ REYS, Sara Esperanza; LUENGO LÓPEZ, Jordi. "Disciplina y violencia contra las mujeres en la prensa del siglo XIX. Divergencia comparativa entre México y España". Revista Estudios Feministas, Florianópolis, v. 29, n. 2, e68349, 2021.

\section{CONTRIBUCIÓN DE AUTORÍA}

Las autoras contribuyeron por igual..

\section{FINANCIACIÓN}

No se aplica.

\section{CONSENTIMIENTO DE USO DE IMAGEN}

No se aplica.

\section{APROBACIÓN DE COMITÉ DE ÉTICA EN INVESTIGACIÓN}

No se aplica.

\section{CONFLICTO DE INTERESES}

No se aplica.

\section{LICENCIA DE USO}

Este artículo tiene la licencia Creative Commons License CC-BY 4.0 International. Con esta licencia puedes compartir, adaptar, crear para cualquier finalidad, siempre y cuando cedas la autoría de la obra.

\section{HISTORIAL}

Recibido el 31/10/2019

Presentado nuevamente el 24/11/2020

Aprobado el 17/12/2020 